\title{
BOAVENTURA DE SOUSA SANTOS E SUAS CONTRIBUIÇÕES PARA A EXTENSÃO UNIVERSITÁRIA NO SÉCULO XXI
}

\author{
Alfredo Almeida Pina-Oliveira \\ Escola de Enfermagem da Universidade de São Paulo \\ alfredopina@usp.br \\ Anna Maria Chiesa \\ Escola de Enfermagem da Universidade de São Paulo \\ amchiesa@usp.br
}

\begin{abstract}
Resumo
As transformações da sociedade demandam oportunidades para que as Instituições de Ensino Superior possam reconhecer suas formas de produção do conhecimento e sua aplicação. A extensão universitária possibilita maior interface entre a Academia, o Mercado e a Sociedade. Elegeu-se a teoria crítica de Boaventura de Sousa Santos com o objetivo de discutir a extensão universitária na perspectiva do "conhecimento pluriversitário", que se apresenta de forma contínua, complementar e contraditória ao conhecimento universitário. As reflexões realizadas possibilitaram a fundamentação teórica de cinco critérios classificatórios relacionados à indissociabilidade ensino, pesquisa e extensão e seu potencial para a translação do conhecimento: ausente, incipiente, regular, relevante e completo. Conclui-se que este autor evidencia elementos importantes para subsidiar a práxis pedagógica inovadora e reforçar as potencialidades das ações extensionistas no enfrentamento dos desafios da reforma do ensino superior no século XXI.

Palavras-chave: Extensão universitária. Relações comunidade-instituição. Difusão de inovações. Conhecimento. Ensino superior.
\end{abstract}

\section{BOAVENTURA DE SOUSA SANTOS AND HIS CONTRIBUTIONS FOR}

\section{ACADEMIC EXTENSION INTO A NEW CENTURY}

\begin{abstract}
Changes in society require opportunities for High Education Institutions may recognize their knowledge creation and its application. Academic extension enables more interfaces among University, Market and Society. We have chosen Boaventura de Sousa Santos' Critical Appraisal in order to discuss "pluriversitary knowledge" that presents continuous, complementary and contradictory type of building universitary knowledge. These reflective thoughts have allowed theorethical underpinning for building five evaluation criteria regarding teaching, research and extension and its potential towards knowledge translation: absent, incipient, regular, relevant and complete. We have concluded that this author evince essential elements to subsidize innovative pedagogical praxis and to boost extension activities up for tackling challenges related to transform Higher Education for 21st century.

Keywords: Academic extension. Community-institutional relations.Diffusion of innovations. Knowledge. Higher Education.

\section{BOAVENTURA DE SOUSA SANTOS Y SUS CONTRIBUCIONES PARA LA EXTENSIÓN UNIVERSITARIA EN EL SIGLO XXI}

Resumen

Las transformaciones de la sociedad exigen oportunidades para que las Instituciones de Enseñanza Superior puedan reconocer sus formas de producción del conocimiento y su aplicación. La extensión universitaria posibilita mayor interface entre la Academia, el Mercado y la Sociedad. Se eligió la teoría critica de Boaventura de Souza Santos con el objetivo de discutir la extensión universitaria en la perspectiva del "conocimiento pluriversitário", que se presenta de forma continua, complementar y contradictoria al conocimiento universitario. Las reflexiones realizadas posibilitan la fundamentación teórica de cinco criterios de clasificación relacionados a la insociabilidad de enseñanza, pesquisa y extensión y su potencial para el traslado del conocimiento ausente, incipiente, regular, relevante e completo. Se concluye 
que este autor revela elementos importantes para subsidiar la praxis pedagógica innovadora y reforzar las potencialidades de las acciones extensionistas en el enfrentamiento de los desafíos de la reforma de la enseñanza superior del siglo XXI.

Palabras clave: Extensión universitaria. Relaciones comunidad-institución. Difusión de invenciones. Conocimiento. Educación Superior. 


\title{
INTRODUÇÃO
}

O presente artigo deriva da construção do objeto de pesquisa "avaliação e indicadores de extensão universitária", doravante extensão, a partir de um referencial teórico de análise pautado em teorias críticas sobre o ensino superior nas áreas de saúde e educação com enfoque na criação e na incorporação de tecnologias para a promoção da saúde (CHIESA et al., 2009) com foco na primeira infância e na promoção do desenvolvimento infantil saudável (CYPEL, 2011; FMCSV, 2011).

A Política Nacional de Extensão Universitária, definida no Fórum de Pró-Reitores de Extensão das Universidades Públicas Brasileiras (FORPROEX, 2012), apresenta em seu prefácio a seguinte síntese do autor Boaventura de Sousa Santos (SANTOS, 2004, p. 53-54) que amplia e valoriza as ações extensionistas, pois:

\begin{abstract}
"A área de extensão vai ter no futuro próximo um significado muito especial. No momento em que o capitalismo global pretende funcionalizar a Universidade e, de fato, transformá-la numa vasta agência de extensão ao seu serviço, a reforma da Universidade deve conferir uma nova centralidade às atividades de extensão (com implicações no currículo e nas carreiras dos docentes) e concebê-las de modo alternativo ao capitalismo global, atribuindo às Universidades uma participação ativa na construção da coesão social, no aprofundamento da democracia, na luta contra a exclusão social e a degradação ambiental, na defesa da diversidade cultural”.
\end{abstract}

Devido ao alinhamento conceitual e metodológico, o presente artigo discorreu sobre o aporte teórico de Boaventura de Sousa Santos (SANTOS, 2001, 2004, 2007, 2008) para entender o papel das Instituições de Ensino Superior (IES) no contexto da crise paradigmática da modernidade que incide sobre as funções acadêmicas e seu papel frente às transformações sociais em âmbito mundial, nacional e local.

O paradigma da modernidade baseia-se em dois pilares de conhecimento: da regulação e da emancipação (SANTOS, 2001), que são sintetizados, de forma bastante elucidativa, por Pereira e Carvalho (2008, p. 46-47):

\footnotetext{
"Os pontos extremos do primeiro são o caos (ignorância) e a ordem (conhecimento); do segundo são o colonialismo (ignorância) e a solidariedade (conhecimento). O pilar da regulação é composto pelo Estado, o mercado e a comunidade, enquanto no pilar da emancipação encontramos três formas de racionalidade: a estético-expressiva, a cognitivo-instrumental e por último a racionalidade prático-moral do direito".
}

No pilar da regulação, o mercado sobrepuja o papel do Estado e da comunidade. No pilar da emancipação, a ciência torna-se a forma hegemônica de racionalidade cognitivo-instrumental. Isso implica, respectivamente, na "hipercientificização da emancipação" e na “hipermercadorização da regulação” descritas por Santos (2001). 
Em relação aos efeitos dessa transição epistemológica e societal, Santos (2004) aponta três crises na Universidade do século XX, a crise da hegemonia, a crise da legitimidade e a crise institucional.

A primeira está embasada na perda da exclusividade da Universidade sobre a produção científica, cultural e humanística de nível elevado e na descaracterização intelectual decorrente da demanda de padrões culturais médios e de conhecimentos instrumentais para a formação da força de trabalho exigida pelo desenvolvimento econômico capitalista (SANTOS, 2004; SANTOS, ALMEIDA FILHO, 2008).

A segunda compreende a crescente segmentação do setor universitário e desvalorização dos diplomas universitários resultante da contradição entre a hierarquização dos saberes especializados que restringiam o acesso às Universidades e a reivindicação de políticas democráticas e inclusivas que permitiriam acesso às camadas populares no ensino superior (SANTOS, 2004; SANTOS, ALMEIDA FILHO, 2008).

A última representa a contradição entre a autonomia na definição dos valores e objetivos acadêmicos ante ao estabelecimento de critérios de eficácia e de produtividade de natureza empresarial ou de responsabilidade social no âmbito das Universidades (SANTOS, 2004; SANTOS, ALMEIDA FILHO, 2008).

Santos e Almeida Filho (2008, p. 59) agregam reflexões importantes à discussão sobre as mudanças ocorridas nas Universidades no século passado e suas potenciais influências no ensino superior na atualidade:

\footnotetext{
"As reformas devem partir do pressuposto que no século XXI só há universidade quando há formação graduada e pós-graduada, pesquisa e extensão. Sem qualquer destes, há ensino superior, não há universidade. Isto significa que, em muitos países, a esmagadora maioria das universidades privadas e mesmo parte das universidades públicas não são universidades porque lhes falta a pesquisa ou a pós-graduação."
}

Apesar de os autores acima enfatizarem as Universidades públicas (federais, estaduais e municipais), a reforma democrática e emancipatória na formação dos profissionais do século XXI deve ser extrapolada para as IES de diferentes naturezas técnico-administrativas (ITAMARATY, 2014), a saber: empresariais, comunitárias e confessionais que exercem, em maior ou menor amplitude, as diversas modalidades de ações extensionistas, tais como projetos, programas, cursos e eventos. 


\section{MATERIAIS E MÉTODOS}

Trata-se de um ensaio reflexivo suportado pelo aporte teórico e crítico de Boaventura de Sousa Santos (SANTOS, 2004, 2005, 2007, 2010; SANTOS, ALMEIDA FILHO, 2008) com o objetivo de discutir a extensão universitária na perspectiva do "conhecimento pluriversitário" com o intuito de apresentar suas principais características, possibilidades e desafios para a construção de ações extensionistas inovadoras.

Para tanto, realizou-se uma revisão da literatura de Boaventura de Sousa Santos e suas reflexões sobre a Universidade do século XXI a fim de compreender os elementos-chave de uma teoria crítica para a construção de um quadro teórico de análise para sustentar a elaboração de indicadores de extensão à luz da translação do conhecimento (TC).

A TC compreende uma das teorias do conhecimento para a ação e visa promover estratégias para a redução da lacuna existente entre a produção de evidências científicas, em geral nas Universidades, e sua incorporação em boas práticas e políticas públicas que podem reverberar de forma positiva e transformadora nos serviços locais e na comunidade (PINA-OLIVEIRA, 2014).

Em uma primeira etapa, os textos do autor em questão (SANTOS, 2004, 2005, 2007, 2010; SANTOS, ALMEIDA FILHO, 2008) foram resenhados e houve o levantamento de características relativas ao conhecimento universitário e pluriversitário associado à extensão, sem desconsiderar os processos de trabalho de ensino, pesquisa e gestão das IES.

Em seguida, construiu-se um quadro comparativo a fim de fundamentar a proposição de um esquema analítico para a avaliação de extensão inovadora embasado nas características supramencionadas e sua potencial indicação do movimento de TC em cursos de Enfermagem, Pedagogia, Psicologia, Fisioterapia e Terapia Ocupacional com foco na Promoção da Saúde durante a Primeira Infância (PINA-OLIVEIRA, 2014).

Por fim, estabeleceram-se os critérios para a classificação da presença de objetos de translação do conhecimento (OTC), ou seja, a "síntese de evidências científicas em conteúdos inovadores" de uma determinada área do conhecimento (no caso, as evidências científicas relacionadas à promoção do desenvolvimento infantil saudável) e a proposição de indicadores de extensão inovadora (PINA-OLIVEIRA, 2014) alinhados às mudanças das relações entre as IES e os sistemas educacionais (FRENK et al, 2010). 


\section{RESULTADOS E ANÁLISES}

Sobre as características do conhecimento pluriversitário, as contribuições de Santos e Almeida Filho (2008) ajudam a compor um continum entre dois extremos ideais, contraditórios e complementares, o conhecimento universitário e o conhecimento pluriversitário (Quadro 1) que permeiam as funções acadêmicas das IES, isto é, a tríade acadêmica composta pelo ensino, pesquisa e extensão.

\begin{tabular}{|l|l|}
\hline Universitário & Pluriversitário \\
\hline $\begin{array}{l}\text { Enfase na produção do } \\
\text { conhecimento }\end{array}$ & $\begin{array}{l}\text { Enfase na coprodução e aplicação do } \\
\text { conhecimento }\end{array}$ \\
\hline Foco nos pesquisadores & Foco nos pesquisadores e utilizadores \\
\hline $\begin{array}{l}\text { Objetivos e ritmos da investigação } \\
\text { são definidos pela equipe de } \\
\text { pesquisadores }\end{array}$ & $\begin{array}{l}\text { Objetivos e ritmos da investigação } \\
\text { são compartilhados pelos } \\
\text { pesquisadores e participantes }\end{array}$ \\
\hline $\begin{array}{l}\text { Metodologias de pesquisa baseadas na } \\
\text { neutralidade científica }\end{array}$ & $\begin{array}{l}\text { Metodologias participativas de } \\
\text { investigação e pesquisa-ação }\end{array}$ \\
\hline $\begin{array}{l}\text { Conhecimento hegemônico, } \\
\text { homogêneo e hierarquizado entre } \\
\text { pares }\end{array}$ & $\begin{array}{l}\text { Conhecimento contextual, } \\
\text { heterogêneo e mediado por atores } \\
\text { sociais relevantes }\end{array}$ \\
\hline $\begin{array}{l}\text { Verticalização absoluta do } \\
\text { conhecimento científico }\end{array}$ & $\begin{array}{l}\text { Redução de assimetrias entre os } \\
\text { diferentes conhecimentos }\end{array}$ \\
\hline $\begin{array}{l}\text { Menor responsabilidade social } \\
\text { relacionada à aplicação das } \\
\text { descobertas científicas }\end{array}$ & $\begin{array}{l}\text { Princípio organizador da produção } \\
\text { científica é a aplicação do } \\
\text { conhecimento }\end{array}$ \\
\hline $\begin{array}{l}\text { "Fixaçãodefronteiras" disciplinares e } \\
\text { multidisciplinares }\end{array}$ & $\begin{array}{l}\text { "Construção de novos caminhos" } \\
\text { inter/transdisciplinares }\end{array}$ \\
\hline Sistemas mais rígidos e lineares & Sistemas mais abertos e complexos \\
\hline $\begin{array}{l}\text { Unilateralidade entre a Universidade e } \\
\text { a Sociedade }\end{array}$ & $\begin{array}{l}\text { Interatividade potencializada pelas } \\
\text { tecnologias de informação e } \\
\text { comunicação }\end{array}$ \\
\hline Formação profissional e crítica & Formação cidadã e solidária \\
\hline Quadro 1 - Características do conhecimento universitário e pluriversitário. São Paulo, 2016. \\
\hline \multicolumn{1}{|c|}{ Fonte: adado de Santos e Almeida Filho (2008). } \\
\hline
\end{tabular}

O quadro acima reforça a necessidade de uma transição paradigmática do ensino universitário para o pluriversitário defendida por Santos e Almeida Filho (2008, p. 10) e revela a "necessidade de abertura da instituição acadêmica para a sociedade que a abriga e sustenta, indo além do Estado e do mercado, incluindo família e movimentos sociais".

Tal distinção ajuda a entender o posicionamento político da Universidade que prima pelo acúmulo do conhecimento científico, mas que pouco ou quase não cria espaços de reflexão sobre 
os efeitos de tais descobertas acadêmicas no enriquecimento ou no empobrecimento do cotidiano e da vida (SANTOS, 2008), fundamentando criticamente o esquema analítico (Quadro 2), a saber:

\begin{tabular}{|l|l|l|l|}
\hline Classificação & Valor & Descrição & Tipo de Conhecimento \\
\hline Ausente & 1 & $\begin{array}{l}\text { Inexistência de OTC nos } \\
\text { conteúdos das disciplinas, } \\
\text { nas ações de pesquisa e de } \\
\text { extensão da IES avaliada }\end{array}$ & $\begin{array}{l}\text { Predominância do conhecimento } \\
\text { universitário e oportunidade } \\
\text { quase nula de TC }\end{array}$ \\
\hline Incipiente & 2 & $\begin{array}{l}\text { Presença de OTC apenas } \\
\text { nos conteúdos e atividades } \\
\text { de ensino da IES avaliada }\end{array}$ & $\begin{array}{l}\text { Predominância do conhecimento } \\
\text { universitário e baixa } \\
\text { oportunidade de TC }\end{array}$ \\
\hline Regular & 3 & $\begin{array}{l}\text { Presença de OTC no } \\
\text { ensino e na pesquisa da IES } \\
\text { avaliada }\end{array}$ & $\begin{array}{l}\text { Predominância do conhecimento } \\
\text { universitário e potencial } \\
\text { oportunidade de TC }\end{array}$ \\
\hline Relevante & 4 & $\begin{array}{l}\text { Presença de OTC na } \\
\text { extensão e no ensino da } \\
\text { IES avaliada }\end{array}$ & $\begin{array}{l}\text { Transição para o conhecimento } \\
\text { pluriversitário e potencial } \\
\text { oportunidade de TC }\end{array}$ \\
\hline Completa & 5 & $\begin{array}{l}\text { Presença de OTC baseada } \\
\text { na indissociabilidade entre } \\
\text { extensão, ensino e pesquisa } \\
\text { na IES avaliada }\end{array}$ & $\begin{array}{l}\text { Predominância do conhecimento } \\
\text { pluriversitário e alta oportunidade } \\
\text { de TC }\end{array}$ \\
\hline
\end{tabular}

Quadro 2 - Critérios de avaliação e indicadores de extensão inovadora à luz do conhecimento pluriversitário. São Paulo, 2016. Fonte: adaptado de PINA-OLIVEIRA et al., 2014.

Os critérios acima foram empregados para a avaliação e a construção de indicadores de extensão inovadora, isto é, uma práxis pedagógica que prima pela indissociabilidade ensinopesquisa-extensão e que incorpora evidências científicas sem prescindir do diálogo e da construção de parcerias com os atores sociais relevantes dos serviços locais e da comunidade na qual as IES estão inseridas (PINA-OLIVEIRA, 2014).

Em relação às possibilidades de inovação dessa práxis pedagógica, Frenket al. (2010) defendem a construção de sistemas de ensino integrados ao sistema de saúde e de educação que visam responder às necessidades da população, aos interesses de mercado e das comunidades. Sendo assim, o conhecimento pluriversitário pode criar oportunidades para a consolidação do paradigma emergente, pois se trata de (SANTOS, 2008, p. 60):

\footnotetext{
“(...) uma revolução científica que ocorre numa sociedade ela própria revolucionada pela ciência, o paradigma a emergir dela não pode ser apenas um paradigma científico (o paradigma de um conhecimento prudente), tem de ser também um paradigma social (o paradigma de uma vida decente)".
} 
Entende-se que a reforma universitária (Quadro 3) pode favorecer a construção de competências globais e locais dos estudantes em prol da transformação da realidade de um mundo interdependente e do fortalecimento da integração entre ensino, serviços locais e comunidade na qual as IES se inserem (FRENK et al., 2010).

\begin{tabular}{|l|l|l|l|}
\hline Paradigma & Nível & Objetivos & Resultados \\
\hline $\begin{array}{l}\text { Ensino baseado } \\
\text { no currículo } \\
\text { tradicional e } \\
\text { científico }\end{array}$ & Informativo & $\begin{array}{l}\text { Conhecimentos } \\
\text { Habilidades }\end{array}$ & Peritos \\
\hline $\begin{array}{l}\text { Ensino baseado } \\
\text { em competências }\end{array}$ & Formativo & $\begin{array}{l}\text { Valores e atitudes } \\
\text { Socialização }\end{array}$ & Profissionais \\
\hline $\begin{array}{l}\text { Ensino baseado } \\
\text { nas necessidades } \\
\text { dos sistemas }\end{array}$ & Transformativo & $\begin{array}{l}\text { Atributos de } \\
\text { liderança }\end{array}$ & $\begin{array}{l}\text { Agentes de } \\
\text { mudança }\end{array}$ \\
\hline
\end{tabular}

Quadro 3 - Elementos da reforma nos sistemas de ensino. São Paulo, 2016.

Fonte: adaptado de FRENK et al., 2010.

Freire (2010, p. 27) refuta a noção de extensão que transfere ou comunica sem a participação reflexiva, dialógica e transformadora dos sujeitos envolvidos na (re) construção do conhecimento, pois:

\footnotetext{
“(...) exige uma presença curiosa do sujeito em face do mundo. Requer uma ação transformadora sobre a realidade. Demonstra uma busca constante. Implica em invenção e em reinvenção. Reclama a reflexão crítica de cada um sobre o ato mesmo de conhecer, pelo qual se reconhece conhecendo e, ao reconhecer-se assim, percebe o "como" de seu conhecer e os condicionamentos a qual está submetido seu ato. [...] Conhecer é tarefa de sujeitos, não de objetos. E é como sujeito e somente enquanto sujeito, que o homem pode realmente conhecer".
}

Por esse motivo, as IES não devem se restringir a aspectos tecnológicos e instrumentais e às urgências industriais e mercantis, mas como afirma Santos (2001, 2008), fato que implica na renovação do pensar e do refletir sobre a geração do "conhecimento prudente", que não se limita às evidências científicas e às inovações tecnológicas, mas também inclui a sabedoria prática de uma "vida decente" nos projetos políticos institucionais e na formação em graduação e pósgraduação comprometida com a mudança da realidade.

À guisa de exemplo, a Organização Mundial de Saúde (WORLD HEALTH ORGANIZATION, 2011) recomenda que as reformas do ensino superior em saúde considerem as necessidades sociais dos indivíduos, famílias e comunidades. Para tanto, ações intersetoriais são requeridas entre as IES e os diferentes setores governamentais, empresariais, não governamentais e comunitários a fim de fortalecer e a relevância social do ensino e da aprendizagem na formação profissional, crítica, reflexiva e cidadã. 
A valorização da extensão pode contribuir para a superação das lacunas quantitativas, qualitativas e de relevância social identificadas para aproximar as "becas" das Universidades com o realismo dos "becos" das cidades (MAYFIELD, 2001) e, conforme, Henriques (2013) ampliar a comunicação e divulgação científica do conhecimento a fim de extrapolar pequenos e poucos grupos para a comunidade (local), a sociedade brasileira e, quiçá, mundial (global).

Essas ações devem propiciar o diálogo entre os saberes técnicos e científicos e os saberes popular e cultural, processo que gera novos conhecimentos e potencializa ações emancipatórias, democráticas, solidárias e transformadoras (FREIRE, 1996, 2010; SANTOS, 2004, 2010).

Sobre os desafios da Educação Superior no século XXI, as relações entre Estado, mercado e sociedade compreendem o conhecimento como elemento estratégico para a integração dos sistemas de ensino com os serviços locais, além de desempenhar importante papel nas relações de poder estabelecidas pelos atores sociais envolvidos (CAMARGO JUNIOR, 2009).

Santos e Almeida Filho (2008) evidenciam que a concretização do conhecimento pluriversitário ocorre com mais expressividade nas parcerias entre as Universidades e as iniciativas de mercado. Entretanto, essa situação desvela a globalização neoliberal sob a égide do desenvolvimento econômico e social derivado da difusão do conhecimento produzido pelas IES.

A implementação de spin-off universitários, isto é, centros e agências nas IES que realizam a transferência de tecnologias e a difusão de inovações ilustra esse movimento nas IES e pode acelerar alternativas efetivas e eficientes para a resolubilidade de problemas complexos apresentados pelo Estado, pela sociedade e pelo mercado (ORTÍN et al., 2008).

Contudo, Camargo Junior (2013) alerta para a mercantilização das evidências científicas e inovações tecnológicas com foco no desenvolvimento econômico a fim de evitar o acirramento das iniquidades em diferentes setores da sociedade, corroborando com Santos e Almeida Filho (2008, p. 57), pois:

\footnotetext{
"A resistência tem de envolver a promoção de alternativas de pesquisa, de formação, de extensão e de organização que apontem para a democratização do bem público universitário, ou seja, para o contributo específico da Universidade [e das possibilidades das demais IES] na definição e solução coletivas dos problemas sociais, nacionais e globais".
} 
Nathan, Siang e Shawkataly (2013, p. 115) proporcionam um ponto de inflexão que ilustra o continuum entre o conhecimento universitário e pluriversitário que não reitera apenas a lógica mercantilista, uma vez que as IES:

\footnotetext{
"são compelidas a implementar políticas e estratégias educacionais equilibradas que mesclam abordagens de ensino centrado na indústria e centrado na sociedade em suas agendas [projetos políticos pedagógicos/institucionais]. Enfatiza-se o desenvolvimento da força de trabalho não apenas competente e renomada, mas também egressos com bom caráter e virtudes sociais".
}

As ressalvas de Santos (2010) devem ser consideradas ao repensar o papel democrático e solidário além do tecnológico e científico da Universidade no século XXI. A formação de profissionais e cidadãos deve considerar as potencialidades e os nós críticos decorrentes do “movimento pendular” de incorporação do conhecimento pluriversitário nas IES.

Em suma, a extensão inovadora apresenta potencialidades para articular o ensino e a pesquisa fundamentada na translação do conhecimento (PINA-OLIVEIRA, 2014) a fim de favorecer a formação democrática, solidária e emancipatória que produz boas práticas acadêmicas, mudanças nas IES, parcerias com a comunidade e compromisso social dos futuros profissionais com a mudança da realidade (SANTOS, 2007, 2010).

\section{CONSIDERAÇÕES FINAIS}

O presente ensaio reflexivo visa à síntese das reflexões proporcionadas pela leitura de Boaventura de Sousa Santos que possibilitoua compreensão da extensão como espaço profícuo para a produção de um "conhecimento prudente" baseado nas evidências científicas e nas inovações tecnológicas e que permite a integração entre o ensino, os serviços locais e a comunidade em prol de mudanças, sem desconsiderar a indissociabilidade entre a pesquisa e a extensão universitária.

Contudo, o autor extrapola essa cientificidade da produção de conhecimento e recomenda ações acadêmicas que assumam o compromisso ético, estético e político de construir uma "vida decente" em conjunto com diferentes atores sociais relevantes na comunidade na qual as Instituições de Ensino Superior estão inseridas.

A dinamicidade contida na contradição, na complementaridade e na continuidade entre o conhecimento universitário e o conhecimento pluriversitário permite oportunidades inovadoras para a formação profissional, crítica, reflexiva e cidadã que dialoga com os diferentes saberes a fim de resolver questões sociais contemporâneas e complexas de modo participativo e 
emancipatório. Nesse sentido, espera-se que a avaliação da extensão inovadora das IES indiquem movimentos em prol de práticas relevantes e completas baseadas na indissociabilidade que realiza a translação do "conhecimento prudente para uma vida decente" sinalizada por Boaventura de Sousa Santos.

Em suma, o presente trabalho pretende contribuir, fundamentado em um paradigma crítico, com o enfrentamento do desafio da construção de modelos de avaliação e ou indicadores que apresentem coerência conceitual entre as características ontológicas do conhecimento pluriversitário e as bases teleológicas da translação do conhecimento para a classificação da extensão inovadora para a reforma dos sistemas de ensino superior no século XXI em um mundo cada vez mais interdependente.

\section{REFERÊNCIAS}

HENRIQUES, M. S. A dinâmica da comunicação para a mobilização social nas práticas da extensão universitária. Interfaces - Revista de Extensão, v. 1, n. 1, p. 24-34, 2013. Disponível em: https://www.ufmg.br/proex/revistainterfaces/index.php/IREXT/article/view/6/pdf. Acessoem: 22 abril de 2016.

BOWEN, S.; MARTENS, P. J.A model for collaborative evaluation of university-community partnerships.J. Epidemiol. Community Health, v. 60, p. 902-907, 2006. DOI: 10.1136/jech.2005.040881.

CAMARGO JUNIOR, K. R. Public health and the knowledge industry.Rev. Saúde Pública, v.43, n.6, p. 1078-1083, 2009. DOI: 10.1590/S0034-89102009005000076.

CHIESA, A.M. et al.A construção de tecnologias de atenção em saúde com base na promoção da saúde. Rev. Esc. Enferm. USP [online], v. 43, n. 2, p. 1352-1357, 2009. DOI: 10.1590/S008062342009000600036.

CYPEL, S. (Org.). Fundamentos do desenvolvimento infantil: da gestação aos 3 anos. São Paulo: Fundação Maria CecíliaSoutoVidigal, 2011.

DAVISON, C. M. Knowledge translation: implications for evaluation. In: OTTOSON, J. M.; HAWE, P. (Eds). Knowledge utilization, diffusion, implementation, transfer, and translation: implications for evaluation. New directions for evaluation, n. 124, p. 75-87, 2009. DOI: 10.1002/ev.315.

FRENK, J. et al. Health professionals for a new century: transforming education to strengthen health systems in an interdependent world. The Lancet, v. 376, n. 9756, p. 1923-1958, 2010. DOI: $10.1016 /$ S0140-6736(10)61854-5. 
FUNDAÇÃO MARIA CECÍlIA SOUTO VIDIGAL. Projetos de Intervenção Local: Estratégias para qualificar a atenção à Primeira Infância. São Paulo, 2011.

NOGUEIRA, M. D. P. Políticas de Extensão Universitária Brasileira. Belo Horizonte: Editora UFMG, 2005.

NATHAN, R. J.; SIANG, T. T. G.; SHAWKATALY, O. Universities at the crossroads: industry or society driven? AustralianUniversitiesReview. v. 55, n. 2, p. 111-115, 2013. Disponível em: http://connection.ebscohost.com/c/articles/91526328/universities-crossroads-industry-societydriven. Acesso em: 22 abril de 2016.

MAYFIELD, L. Town and gown in America: some historical and institutional issues of the engaged University. Education for health. v. 14, n. 2, p. 231-240, 2001. Disponível em: http://ejournal.narotama.ac.id/files/Town $\% 20$ and $\% 20$ Gown $\% 20$ in $\% 20$ America $\% 20$ Some $\% 20$

Historical\%20and.pdf. Acesso em: 22 abril de 2016.

ORTÍN, P.; SALAS, V.; TRUJILLO, M.V.; VENDRELL, F. La creación de spinoffuniversitariasenEspaña: características, determinantes y resultados. Economía industrial. v. 368, p. 79-95, 2008. Disponível em: http://www.minetur.gob.es/Publicaciones/Publicacionesperiodicas/EconomiaIndustrial/Revista EconomiaIndustrial/368/79.pdf. Acesso em: 22 abril de 2016.

PINA-OLIVEIRA A. A. et al. Análise do processo de translação do conhecimento sobre a primeira infância no ensino de graduação. Rev. esc. enferm. USP. v. 48, n. spe, p. 160-167, 2014. Disponível em: http://www.scielo.br/scielo.php?script=sci_arttext\&pid=S008062342014000700160\&lng=en\&nrm=iso. Acesso em: 22 abril de 2016.

SANTOS B. S.; ALMEIDA FILHO N. (Org.). A Universidade no século XXI: por uma universidade nova. Coimbra: Almedina, 2008.

SANTOS, B. S. Pela mão de Alice: o social e o político na pós-modernidade. Porto: Afrontamento, 1995.

. A Universidade no século XXI. São Paulo: Cortez Editora, 2004.

A Universidade no século XXI: para uma reforma democrática e emancipatória da Universidade. 3. ed. São Paulo: Cortez Editora, 2010.

Para um novo senso comum: a ciência, o direito e a política na transição paradigmática. A crítica da razão indolente - contra o desperdício da experiência. 3. ed. São Paulo: Cortez, 2001. v. 1.

Renovar a teoria crítica e reinventar a emancipação social. Tradução de Mouzar Benedito. São Paulo: Boitempo, 2007.

Um discurso sobre as ciências. $5^{a}$ ed. São Paulo: Cortez; 2008.

A universidade no século XXI: para uma reforma democrática e emancipatória da universidade. 2.ed. São Paulo: Cortez, 2005. 
Boaventura de Sousa Santos e suas contribuições para a extensão universitária no século XXI

PEREIRA, M. A.; CARVALHO, E. Boaventura de Sousa Santos: por uma nova gramática do político e do social. Lua Nova, v. 73, p. 45-58, 2008 . Disponível em: http://www.scielo.br/pdf/ln/n73/n73a02.pdf. Acesso em: 22 abril de 2016.

STRAUS, S. E.; TETROE, J.; GRAHAM, I. Defining knowledge translation.CMAJ, v. 181, n. 34, p. 165-168, 2009.

WORLD HEALTH ORGANIZATION.Transformative scale up of health professional education.Geneva: World Health Organization, 2011.

FÓRUM DE PRÓ-REITORES DE EXTENSÃO DAS UNIVERSIDADES PÚBLICAS BRASILEIRAS. Indissociabilidade ensino-pesquisa-extensão e a flexibilização curricular: uma visão da extensão. Porto Alegre: UFRGS, 2006. (Coleção Extensão Universitária, v.4). 